\title{
Advanced CT images reveal nonmetric cranial variations in living humans
}

\author{
Naruya SAITOU ${ }^{1}$, Ryosuke KIMURA ${ }^{2}$, Hitoshi FUKASE ${ }^{3}$, Akira YogI $^{4}$, Sadayuki MURAYAMA ${ }^{4}$, Hajime ISHIDA ${ }^{3 *}$ \\ ${ }^{1}$ Division of Population Genetics, National Institute of Genetics, Mishima 411-8540, Japan \\ ${ }^{2}$ Transdisciplinary Research Organization for Subtropics and Island Studies, University of the Ryukyus, Okinawa 903-0215, Japan \\ ${ }^{3}$ Department of Human Biology and Anatomy, Faculty of Medicine, University of the Ryukyus, Okinawa 903-0215, Japan \\ ${ }^{4}$ Department of Radiology, Faculty of Medicine, University of the Ryukyus, Okinawa 903-0215, Japan
}

Received 28 September 2010; accepted 15 October 2010

\begin{abstract}
Two mainland Japanese males were examined with a computer tomography (CT) X-ray scanner to reconstruct three-dimensional CT simulation images of their cranial anatomy and to check for the presence/absence of 23 nonmetric cranial traits. Surface anatomy for scoring 19 nonmetric cranial variations was clearly observed among the 23 variations. Evaluation of the four other traits might have been disturbed due to dental treatment history, small variations in the images, or X-ray radiation condition. However, these disturbances could be overcome by a combination of simple thin-sliced CT images and magnetic resonance imaging. We have thus developed a new anatomical field for elucidating human morphology.
\end{abstract}

Key words: CT image, nonmetric cranial variation, anatomy

\section{Introduction}

Human nonmetric cranial variations have been described worldwide for a long time, alongside other macroscopic variations in human anatomy (e.g. Poirier, 1896). In Japan, Akabori (1933) reported many nonmetric variations using about 200 recent Japanese crania. Hauser and De Stefano (1989) reviewed the gross anatomy, function, development, and genetics of nonmetric cranial variations on the basis of huge previous anatomical studies.

Physical anthropologists have long studied cranial metric data in order to reconstruct population affinities (e.g. Koganei, 1893; Woo and Morant, 1934; Howells, 1973). On the other hand, the application of nonmetric cranial variations to population studies only became popular in the late 20th century (Laughlin and Jörgensen, 1956; Berry and Berry, 1967; and many others).

Yamaguchi (1967), Dodo (1974, 1986a), Ossenberg (1986), and Mouri (1986) have undertaken refined studies of nonmetric cranial traits, which proved effective for reconstructing the Pan-Pacific population history. Yukio Dodo and his collaborators have intensively studied nonmetric cranial traits from the viewpoint of their stability within populations and diversity among populations (Dodo, 1974, 1986a, b, 1987; Dodo and Ishida, 1987, 1990, 1992; Dodo et al., 1992; Ishida and Dodo, 1993, 1997; Dodo et al., 1998; Dodo and Kawakubo, 2002). On the basis of these series of

\footnotetext{
* Correspondence to: Hajime Ishida, Department of Human Biology and Anatomy, Faculty of Medicine, University of the Ryukyus, Uehara 207, Nishihara, Okinawa 903-0215, Japan.

E-mail: ishidaha@med.u-ryukyu.ac.jp

Published online 23 December 2010

in J-STAGE (www.jstage.jst.go.jp) DOI: 10.1537/ase.100928
}

studies, the nonmetric cranial variations of populations worldwide have been investigated (Ishida, 1993, 1995; Hanihara et al., 1998; Ishida and Kondo, 1999; Hanihara and Ishida, 2001a, b, c, d, e; Komesu et al., 2008; Dodo and Sawada, 2010; Nakashima et al., 2010). Furthermore, the efficacy of nonmetric cranial analysis was confirmed with reference to classic genetic and linguistic research on worldwide human populations (Hanihara et al., 2003).

Population studies have been performed on the assumption that the appearance of nonmetric cranial variations is fairly well controlled by genetic factors (Dodo and Ishida, 1990). In fact, the affinity of Ainu and Okinawa populations suggested by Hanihara (1991) was supported by both genetic studies (e.g. Omoto and Saitou, 1997) and by nonmetric study (Fukumine et al., 2006). However, only a limited number of studies have reported the heritability estimates of nonmetric cranial traits based on human family studies, or human or other primate skeletons (Saunders and Popovich, 1978; Cheverud and Buikstra, 1981a, b; Sjøvold, 1984; Mouri, 1997; Velemínský and Dobisíková, 2005).

Recently, the genetics of normal human morphological characteristics has radically evolved through the use of genome-wide association studies and strategies based on population genomics (e.g. Weedon et al., 2008; Fujimoto et al., 2008; Kimura et al., 2009). For example, variation in the $E D A R$ gene determines the presence of shovel-shaped incisors (Kimura et al., 2009), which is one of the major characteristics in East Asian and American peoples (Hanihara, 1966; Haneji et al., 2007). Although these visible characteristics are easily measured using living samples, there have been few genetic studies on human anatomical variants.

The newest and most advanced computer tomography (CT) and magnetic resonance imaging (MRI) methods can evaluate anatomical variations of living human subjects, and 
this has already enabled analysis of the anatomy of the bronchial arteries and their relationships to adjacent nerves and veins (e.g. Oshiro et al., 2009; Morita et al., 2010). Here, we preliminarily applied these up-to-date methods to examine the presence or absence of nonmetric cranial variations in order to obtain basic data for genetic analysis.

\section{Materials and Methods}

\section{Human subjects}

Two mainland Japanese males, subject 1 (a 53-year-old male) and subject 2 (a 35-year-old male), volunteered for CT imaging. They had no previous history of head or neck surgery. Written informed consent was obtained from both individuals following the regulations of the University of the Ryukyus.

\section{CT protocol}

Whole-head CT scans were obtained for the two males with a 320-detector row MDCT scanner (Aquilion One, Toshiba, Tokyo, Japan) using a scanning protocol $(120 \mathrm{kV}$, auto-mA, helical pitch 41.0, small focus, slice thickness; $0.5 \times 64 \mathrm{~mm}$ ) at the University Hospital of the Ryukyus on 22 July 2010.

\section{CT data interpretation}

CT image processing and visualization were carried out using the software Analyze 10.0 (Mayo Clinic, USA). After the three-dimensional reconstruction of CT images, the last author (H.I.) checked for the presence/absence of 23 nonmetric cranial traits defined by Dodo (1974, 1986a). These 23 characteristics are listed in Table 1.

\section{Results}

Figure 1 and Figure 2 show the three-dimensional reconstruction of respective cranial sites of the 23 nonmetric cranial variations, mainly using the CT data of subject 2 because cranial sutures tended to be obliterated in subject 1 . Almost all traits were absent, unfortunately (Table 1). Neither metopism (characteristic no. 1) nor supraorbital nerve groove (characteristic no. 2) was seen on the external surface of the squamous part of the frontal bone (Figure 1a). The supraorbital foramen (characteristic no. 3) on the supraorbital margin was present on the right side, while the supraorbital notch was present on the left side of both subjects (Figure $1 \mathrm{~b}$ and $\mathrm{c}$ ), which shows the unilateral presence of this trait.

From the posterior aspect, the interparietal, or incomplete median Inca bone (Type V, Hanihara and Ishida, 2001a) (characteristic no. 5) was present in subject 1 (Figure 1d, upper). Other wormian bones, including the ossicle at the lambda (characteristic no. 4), biasterionic suture vestige (characteristic no. 6), asterionic bone (characteristic no. 7), occipitomastoid bone (characteristic no. 8), and parietal notch bone (characteristic no. 9), were not found (Figure 1e).

Around the foramen magnum, the left condylar canal (characteristic no. 10) was found just posterior to the occipital condyle, but was not found in the right side (Figure 1f).
Table 1. Nonmetric cranial variations of the two mainland Japanese males

\begin{tabular}{|c|c|c|c|c|c|}
\hline \multirow{2}{*}{ ID no. } & \multirow{2}{*}{ Name of nonmetric characteristic } & \multicolumn{2}{|c|}{ Subject 1} & \multicolumn{2}{|c|}{ Subject 2} \\
\hline & & right & left & right & left \\
\hline 1 & Metopism & \multicolumn{2}{|c|}{ - } & \multicolumn{2}{|c|}{-} \\
\hline 2 & Supraorbital nerve groove & - & - & - & - \\
\hline 3 & Supraorbital foramen & + & - & + & - \\
\hline 4 & Ossicle at lambda & \multicolumn{2}{|c|}{-} & \multicolumn{2}{|c|}{-} \\
\hline 5 & Interparietals (Inca bone) & \multicolumn{2}{|c|}{+} & \multicolumn{2}{|c|}{ - } \\
\hline 6 & Biasterionic suture vestige & - & - & - & - \\
\hline 7 & Asterionic bone & - & - & - & - \\
\hline 8 & Occipito-mastoid bone & ? & ? & - & - \\
\hline 9 & Parietal notch bone & - & - & - & - \\
\hline 10 & Condylar canal patent & $?$ & $?$ & - & + \\
\hline 11 & Precondylar tubercle & - & - & - & - \\
\hline 12 & Paracondylar process & - & - & - & - \\
\hline 13 & Hypoglossal canal bridging & $?$ & - & - & - \\
\hline 14 & Tympanic dehiscence & $?$ & $?$ & ? & $?$ \\
\hline 15 & Ovale-spinosum confluence & - & - & - & - \\
\hline 16 & Pterygo-spinous foramen & - & - & - & - \\
\hline 17 & Foramen of Vesalius & - & + & - & - \\
\hline 18 & Medial palatine canal & $?$ & $?$ & $?$ & $?$ \\
\hline 19 & Transverse zygomatic suture vestige & $?$ & $?$ & - & - \\
\hline 20 & Clinoid bridging & $?$ & $?$ & - & - \\
\hline 21 & Mylohyoid bridging & - & - & - & - \\
\hline 22 & Jugular foramen bridging & - & - & - & - \\
\hline 23 & Sagittal groove left & \multicolumn{2}{|c|}{ - } & \multicolumn{2}{|c|}{-} \\
\hline
\end{tabular}

+, present; -, absent; ?, unknown

There were no precondylar tubercles (characteristic no. 11) and paracondylar processes (characteristic no. 12) (Figure 1g). Although we could see the hypoglossal canal (characteristic no. 13) from the inner aspect of the foramen magnum, the bridging was not found in subject 2 (Figure 1h). In the inferior view of the tympanic part of the temporal bone, it was difficult to judge the presence of the tympanic dehiscence (Foramen of Huschke) (characteristic no. 14), as shown in Figure 1i. The spine of sphenoid bone was clearly recognized and the pterygospinous foramen (characteristic no. 16) was not present in this case.

Figure 2a shows the upper view of the foramen ovale and foramen spinosum from the inner side. Because the foramen ovale and foramen spinosum are normally separated by a bony structure, the ovale-spinosum confluence (characteristic no. 15) was not seen. The foramen of Vesalius (characteristic no. 17) was also not recognized in subject 2 (Figure 2a). However, a simple horizontal slice at the level of the foramina ovale and spinosum in subject 1 showed that the foramen of Vesalius was present just anterior to the foramen ovale on the left side (Figure 2b).

Figure $2 \mathrm{c}$ represents the inferior aspect of the hard palate and alveolar process. Both subjects had a previous history of dental treatment, and a large amount of noise from metal on the crown disturbed the three-dimensional reconstruction of the hard palate. Therefore, we could not see the medial palatine groove or canal (characteristic no. 18).

The temporozygomatic suture can be faintly seen in Figure 2d. Although we judged that the transverse zygomatic suture vestige (characteristic no. 19) was not present in this case, it may be difficult to identify it. Figure 2 e shows the internal cranial fossa from above. The anterior and 


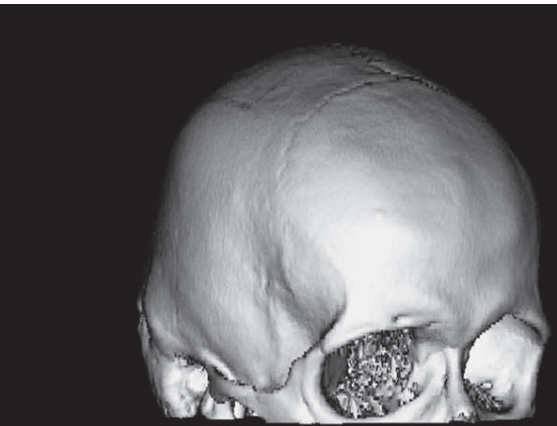

(a)

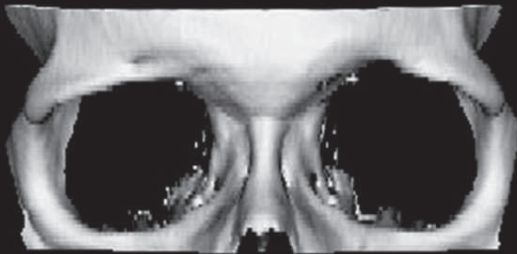

(b)

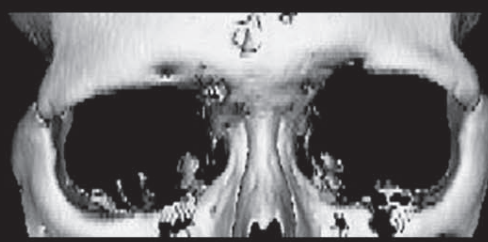

(c)
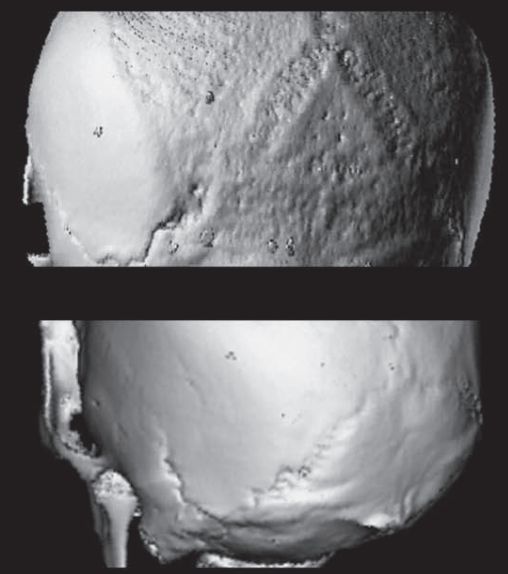

(d)

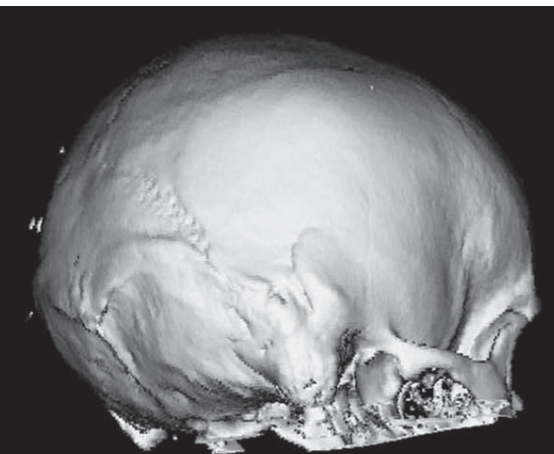

(e)

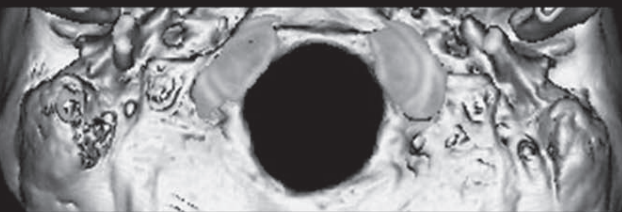

(f)

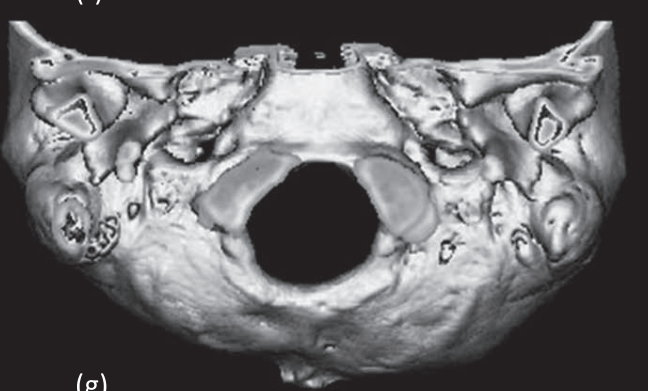

(g)

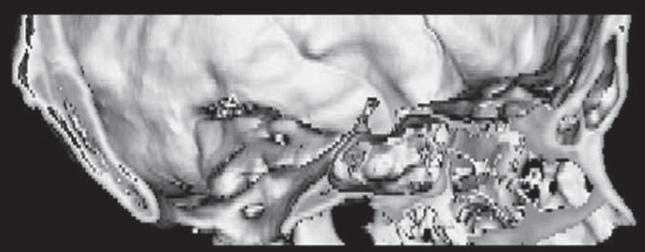

(h)

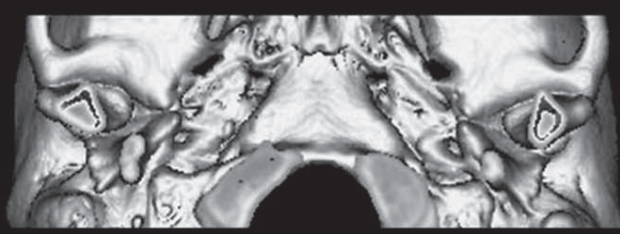

(i)

Figure 1. Three-dimensional CT simulation images of cranial anatomy in the two Japanese male subjects. (a) Neurocranium viewed from right anterior-superior side. (b) Orbitae viewed from frontal side of subject 2 . The supraorbital foramen on the right and supraorbital notch on the left of the supraorbital margin are present. (c) Orbitae viewed from frontal side of subject 1 . The supraorbital foramen on the right and supraorbital notch on the left of the supraorbital margin are present. (d) Neurocrania viewed from left posterior-superior side. The upper cranium had an Inca bone (incomplete median type, Hanihara and Ishida, 2001a). (e) Neurocranium viewed from right posterior-lateral side. The lambdoid, occipitomastoid, and squamous sutures are seen. No wormian bones are present within them. (f) Basicanium viewed from inferior side. The right condylar canal is present just posterior to the occipital condyle. (g) Basicanium viewed from inferior side. No precondylar tubercles are seen in the front of the foramen magnum. The paracondylar process is not present lateral to the occipital condyle. (h) Intracranial view enables clear visualization of the hypoglossal canal and related structure. (i) Basicranium from inferior side. The inferior aspect of the tympanic part of the temporal bone and the spine of the sphenoid bone are observed. The pterygospinous foramen is not present. 


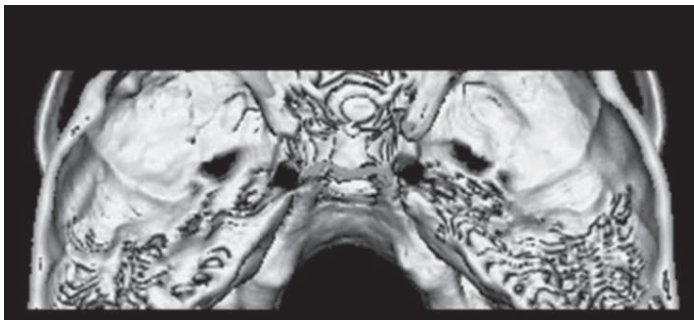

(a)
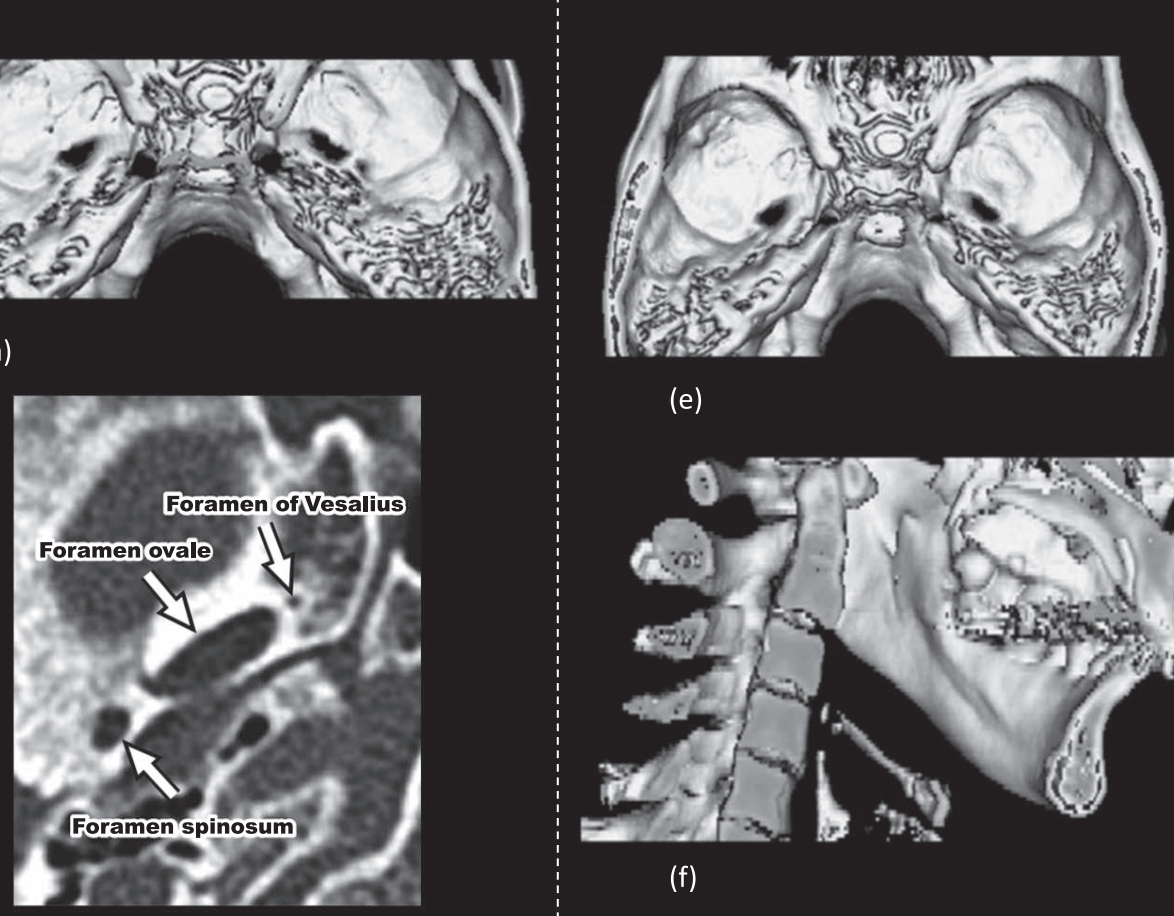

(b)

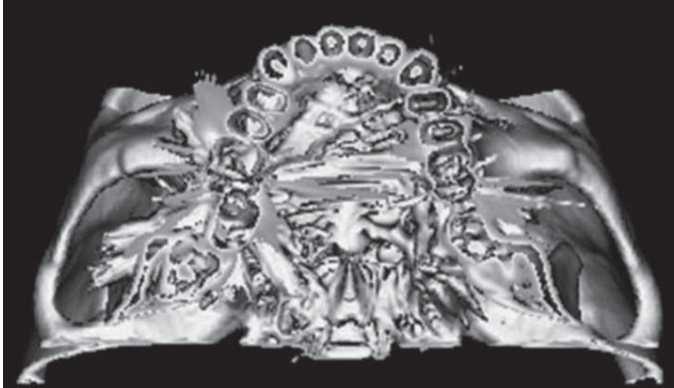

(c)

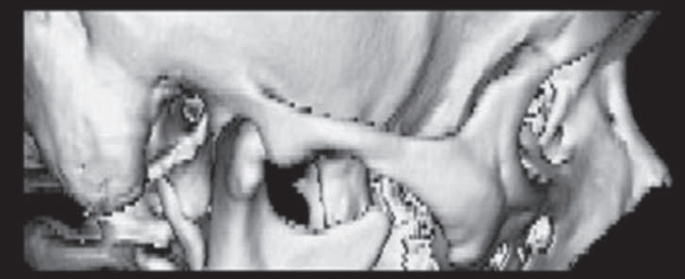

(d)

(e)

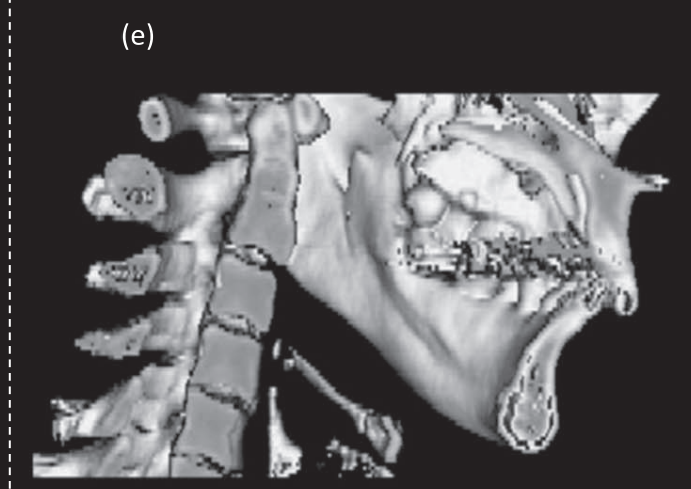

(f)

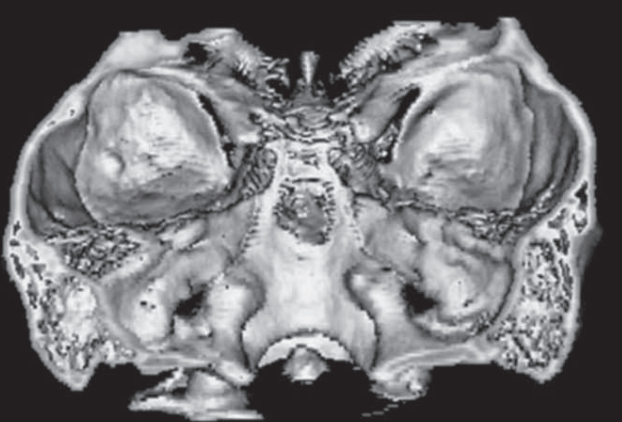

(g)

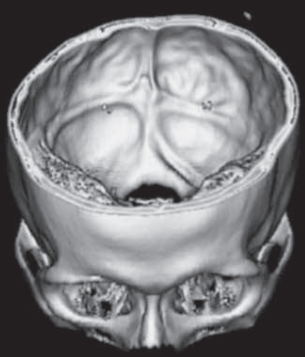

(h)

Figure 2. Three-dimensional CT simulation and axial CT images of cranial anatomy in the two Japanese male subjects. (a) Middle cranial fossa viewed from superior side. The foramina of ovale and spinosum are observed. There is no ovale-spinosum confluence or foramen of Vesalius. (b) Axial CT image at the level of the foramina ovale and spinosum of subject 1 shows the foramen of Vesalius just anterior-medial to the foramen ovale on the left side. (c) The hard palate viewed from the inferior side. Structures of the hard palate cannot be seen owing to noise from dental metal. (d) The zygomatic arch viewed from the lateral side. The temporozygomatic suture is barely visible. The transverse zygomatic suture may not be present. (e) The body of the sphenoid bone viewed from above. The anterior and posterior clinoid processes are observed. There is no clinoid bridging. (f) Inner aspect of the ramus of mandible. The mandibular foramen, lingula, and mylohyoid groove are observed. (g) Posterior cranial fossa viewed from the posterior side. The bilateral jugular foramina with no bridging are seen. (h) Posterior cranial fossa viewed from the antero-superior side. Both grooves for superior sagittal sinus turn to the right. 
posterior clinoid processes of the body of sphenoid bone were seen but the middle clinoid process was not, indicating that there was no clinoid bridging (characteristic no. 20) in this case.

The inner aspect of the ramus of mandible is seen in Figure $2 \mathrm{f}$. The mandibular foramen, lingula and mylohyoid groove were completely observed. Unfortunately, the mylohyoid bridging (characteristic no. 21) was not present. A three-dimensional image of the posterior cranial fossa of the superior-posterior aspect was reconstructed (Figure 2g). The jugular foramina, which were continuous from the groove for the sigmoid sinus, were seen, but there was no bridging (characteristic no. 22).

Finally, Figure $2 \mathrm{~h}$ shows the inner surface of the occipital bone, in which several sinus grooves were present. The groove for the superior sagittal sinus (characteristic no. 23) turned to the right in both subjects.

\section{Discussion}

Bone surface anatomy for 19 nonmetric cranial variations was clearly observed among the 23 variations using this three-dimensional reconstruction from CT images.

The suture variations were not easily detected in the older subject because of suture closure on the external surface. The temporozygomatic suture was not easily observed even in the younger case to score the transverse zygomatic suture. We should improve the X-ray radiation conditions because a clinical study was able to reveal the feature of the temporozygomatic suture (Boeddinghaus and Whyte, 2008).

The two small foramina of the tympanic dehiscence and the foramen of Vesalius could not be detected on the basis of our three-dimensional images. However, we found the foramen of Vesalius on the simple thin-sliced horizontal CT image, as shown in clinical cases (Borges, 2008a). Both threedimensional and thin-sliced CT images must be combined to find small variations in the foramen.

The hard palate was not seen in these cases because of metal from dental treatments. We need to select other subjects for observation of the hard palate and palatine grooves.

In summary, we would in the future like to examine younger and healthy humans to observe sutures and tiny variations using more refined radiation conditions.

Clinical medicine has investigated not only pathological conditions but also normal variation using CT scanning (Boeddinghaus and Whyte, 2008; Borges, 2008a, b; Goh et al., 2008; Lemmerling et al., 2008; Maroldi et al., 2008). However, because nonmetric cranial variations were often not noticed, this study is quite new.

Nerves and vessels pass through some foramina, including the jugular foramen and hypoglossal canal. The glossopharyngeal, vagus, and accessory nerves pass through the jugular foramen, and the hypoglossal nerve passes into the hypoglossal canal. CT clearly displays bony anatomy while MRI can directly visualize nerves (Alves, 2010; Borges and Casselman, 2010; Kang and Hin, 2010). In order to confirm the existence of the bridging of those foramina, it is better to combine CT and MRI methods simultaneously. In fact, the two subjects underwent a preliminary MRI investigation: the nerves were clearly observed, and no bony bridging was de- tected (data not shown).

In this study, we definitively showed that cranial anatomy can be used to score nonmetric cranial variations based on CT data from living humans. Thus, these data can be directly compared with huge amounts of genetic data of the same individuals; to date, only osteological analyses have been used to infer heritability (Sanchez-Lara et al., 2007). We will gather much anatomical and genetic data from the same individuals under the approval of our ethical committee to elucidate the morphological background of the human body.

\section{Acknowledgments}

We are deeply grateful to the radiological technologists at the University Hospital of the Ryukyus for radiographic imaging. This study was supported in part by a Grant-in-Aid for Scientific Research (No. 22687023) from the Japan Society for the Promotion of Science.

\section{References}

Akabori E. (1933) Crania Nipponica Recentia. I. Analytical inquiries into the non-metric variations in the Japanese skull according to age and sex. Japanese Journal of Medical Science, Section 1, Anatomy, 4: 61-315.

Alves P. (2010) Imaging the hypoglossal nerve. European Journal of Radiology, 74: 368-377.

Berry A.C. and Berry R.J. (1967) Epigenetic variation in the human cranium. Journal of Anatomy, 101: 361-379.

Boeddinghaus R. and Whyte A. (2008) Current concepts in maxillofacial imaging. European Journal of Radiology, 66: 396418.

Borges A. (2008a) Skull base tumours part I. Imaging technique, anatomy and anterior skull base tumours. European Journal of Radiology, 66: 338-347.

Borges A. (2008b) Skull base tumours part II. Central skull base tumours and intrinsic tumours of the bony skull base. European Journal of Radiology, 66: 348-362.

Borges A. and Casselman J. (2010) Imaging the trigeminal nerve. European Journal of Radiology, 74: 323-340.

Cheverud J.M. and Buikstra J. (1981a) Quantitative genetics of skeletal non-metric traits in the Rhesus macaques of Cayo Santiago. I. Single trait heritability. American Journal of Physical Anthropology, 54: 43-49.

Cheverud J.M. and Buikstra J. (1981b) Quantitative genetics of skeletal non-metric traits in the Rhesus macaques of Cayo Santiago. II. Phenotypic, genetic and environmental correlations between traits. American Journal of Physical Anthropology, 54: 51-58.

Dodo Y. (1974) Non-metrical cranial traits in the Hokkaido Ainu and the northern Japanese of recent times. Journal of the Anthropological Society of Nippon, 82: 31-51.

Dodo Y. (1986a) A population study of the jugular foramen bridging of the human cranium. American Journal of Physical Anthropology, 69: 15-19.

Dodo Y. (1986b) Metrical and non-metrical analyses of Jomon crania from eastern Japan. In: Akazawa T. and Aikens C.M. (eds.), Prehistoric Hunter-Gatherers in Japan. University of Tokyo Press, Tokyo, pp. 137-161.

Dodo Y. (1987) Supraorbital foramen and hypoglossal canal bridging: the two most suggestive nonmetric cranial traits in discriminating major racial grouping of man. Journal of the Anthropological Society of Nippon, 95: 19-35.

Dodo Y. and Ishida H. (1987) Incidence of nonmetric cranial variants in several population samples from East Asia and North America. Journal of the Anthropological Society of Nippon, 
95: 161-177.

Dodo Y. and Ishida H. (1990) Population history of Japan as viewed from cranial nonmetric variation. Journal of the Anthropological Society of Nippon, 98: 269-287.

Dodo Y. and Ishida H. (1992) Consistency of nonmetric cranial trait expression during the last 2,000 years in the habitants of the central islands of Japan. Journal of the Anthropological Society of Nippon, 100: 417-423.

Dodo Y. and Kawakubo Y. (2002) Cranial affinities of the EpiJomon inhabitants in Hokkaido, Japan. Anthropological Science, 110: 1-32.

Dodo Y. and Sawada J. (2010) Supraorbital foramen and hypoglossal canal bridging revisited: their worldwide frequency distribution. Anthropological Science, 118: 65-71.

Dodo Y., Ishida H., and Saitou N. (1992) Population history of Japan: a cranial nonmetric approach. In: Akazawa T., Aoki $\mathrm{K}$, and Kimura T. (eds.), The Evolution and Dispersal of Modern Humans in Asia. Hokusen-sha, Tokyo, pp. 479-492.

Dodo Y., Doi N., and Kondo O. (1998) Ainu and Ryukyuan cranial nonmetric variation: evidence which disputes the AinuRyukyu common origin theory. Anthropological Science, 106: 99-120.

Fujimoto A., Kimura R., Ohashi J., Omi K., Yuliwulandari R., Batubara L., Mustofa M.S., Samakkarn U., Setteethan-Ishida W., Ishida T., Morishita Y., Furusawa T., Nakazawa M., Ohtsuka R., and Tokunaga K. (2008) A scan for genetic determinants of human hair morphology: EDAR is associated with Asian hair thickness. Human Molecular Genetics, 17: 835-843.

Fukumine T., Hanihara T., Nishime A., and Ishida H. (2006) Nonmetric cranial variation of early modern human skeletal remains from Kumejima, Okinawa and the peopling of the Ryukyu Islands. Anthropological Science, 114: 141-151.

Goh P.S., Gi M.T., Charlton A., Tan C., Gangadhara Sundar J.K., and Amrith S. (2008) Review of orbital imaging. European Journal of Radiology, 66: 387-295.

Haneji K., Hanihara T., Sunakawa H., Toma T., and Ishida H. (2007) Nonmetric dental variation of Sakishima Islands, Okinawa, Japan: a comparative study among Sakishima and other neighboring populations. Anthropological Science, 115: 3545 .

Hanihara K. (1966) Mongoloid dental complex in the deciduous dentition. Journal of the Anthropological Society of Nippon, 74: $61-72$

Hanihara K. (1991) Dual structure model for the population history of the Japanese. Japan Review, 2: 1-33.

Hanihara T. and Ishida H. (2001a) Os incae: frequency variation in major human population groups. Journal of Anatomy, 198: $137-152$.

Hanihara T. and Ishida H. (2001b) Frequency variations of discrete cranial traits in major human populations. I. Supernumerary ossicle variations. Journal of Anatomy, 198: 689-706.

Hanihara T. and Ishida H. (2001c) Frequency variations of discrete cranial traits in major human populations. II. Hypostotic variations. Journal of Anatomy, 198: 707-725.

Hanihara T. and Ishida H. (2001d) Frequency variations of discrete cranial traits in major human populations. III. Hyperostotic variations. Journal of Anatomy, 199: 251-272.

Hanihara T. and Ishida H. (2001e) Frequency variations of discrete cranial traits in major human populations. IV. Vessels and nerve related variations. Journal of Anatomy, 199: 273-287.

Hanihara T., Ishida H., and Dodo Y. (1998) Os zygomaticum bipartitum: the frequency distribution in major human populations. Journal of Anatomy, 192: 539-555.

Hanihara T., Ishida H., and Dodo Y. (2003) Characterization of biological diversity through analysis of discrete cranial traits. American Journal of Physical Anthropology, 121: 241-251.

Hauser G. and De Stefano G.F. (1989) Epigenetic Variants of the Human Skull. E. S Schweizerbart'sche Verlagsbuchhandlung, Stuttgart.
Howells W.W. (1973) Cranial Variation in Man. Papers of the Peabody Museum of Archaeology and Ethnology, Harvard University, 67.

Ishida H. (1993) Populational affinities of the Peruvian with Siberians and North Americans: a nonmetric cranial approach. Anthropological Science, 101: 47-63.

Ishida H. (1995) Nonmetric cranial variation of Northeast Asian populations and their population affinities. Anthropological Science, 103: 385-401

Ishida H. and Dodo Y. (1993) Nonmetric cranial variation and the populational affinities of the Pacific peoples. American Journal of Physical Anthropology, 90: 49-57.

Ishida H. and Dodo Y. (1997) Cranial variation in prehistoric human skeletal remains from the Marianas. American Journal of Physical Anthropology, 105: 399-410.

Ishida H. and Kondo O. (1999) Nonmetric cranial variation of the Ainu and neighbouring human populations. Perspectives in Human Biology, 4: 127-138.

Kang O.C. and Hin C.V.F. (2010) The glossopharyngeal, vagus and spinal accessory nerves. European Journal of Radiology, 74: 359-367.

Kimura R., Yamaguchi T., Takeda M., Kondo O., Toma T., Haneji K., Hanihara T., Matsukusa H., Kawamura S., Maki K., Osawa M., Ishida H., and Oota H. (2009) A common variation in $E D A R$ is a genetic determinant of shovel-shaped incisors. American Journal of Human Genetics, 83: 528-535.

Koganei Y. (1893) Beiträge zur physischen Anthropologie der Aino. I. Untersuchungen am Skelet. Mitteilungen aus der medicinischen Facultät der kaiserlich-japanischen Universität, vol. 2, pp. 1-249 (in German).

Komesu A., Hanihara T., Amano T., Ono H., Yoneda M., Dodo Y., Fukumine T., and Ishida H. (2008) Nonmetric cranial variation in human skeletal remains associated with Okhotsk culture. Anthropological Science, 116: 33-47.

Laughlin W.S. and Jörgensen J.B. (1956) Isolate variation in Greenlandic Eskimo crania. Acta Genetica, 6: 3-12.

Lemmerling M.M., De Foer B., Vande Vyver V., Vercrusse J.P., and Verstraete K.L. (2008) Imaging of the opacified middle ear. European Journal of Radiology, 66: 363-371.

Maroldi R., Ravanelli M., Borghesi A., and Farina D. (2008) Paranasal sinus imaging. European Journal of Radiology, 66: 372-386.

Morita Y., Takase K., Ichikawa H., Yamada T., Sato A., Higano S., and Takahashi S. (2010) Bronchial artery anatomy: preoperative 3D simulation with multidetector CT. Radiology, 255: 934-943.

Mouri T. (1986) Geographical and temporal variation in Japanese populations as viewed from nonmetric traits of the skull. Ph.D. thesis, Kyoto University, pp. 1-79 (in Japanese).

Mouri T. (1997) Divided hypoglossal canals in Japanese macaques. Anthropological Science, 105: 211-216.

Nakashima A., Ishida H., Shigematsu M., Goto M., and Hanihara T. (2010) Nonmetric cranial variation of Jomon Japan: implications for the evolution of eastern Asian diversity. American Journal of Human Biology, 22: 782-790.

Omoto K. and Saitou N. (1997) Genetic origins of the Japanese: a partial support for the 'dual structure hypothesis.' American Journal of Physical Anthropology, 102: 437-446.

Oshiro Y., Murayama S., Miyagi S., Nakamoto A., Ohta M., and Ishikawa K. (2009) Simultaneous occurrence of partial anomalous pulmonary venous return and major bronchial anomaly: computed tomography findings in 5 adult patients. Journal of Computer Assisted Tomography, 33: 535-539.

Ossenberg N.S. (1986) Isolate conservatism and hybridization in the population history of Japan: The evidence of nonmetric cranial traits. In: Akazawa T. and Aikens C.M. (eds.), Prehistoric HunterGatherers in Japan. University of Tokyo Press, Tokyo, pp. 199-215.

Poirier P. (1896) Traité D’Anatomie Humaine, Tom. 1. L. Battaille et C., Paris. 
Sanchez-Lara P.A., Graham Jr J.M., Hing A.V., Lee J., and Cunningham M. (2007) The morphogenesis of wormian bones: a study of craniosynostosis and purposeful cranial deformation. American Journal of Medical Genetics A, 143A: 3243-3251.

Saunders S.R. and Popovich F. (1978) A family study of two skeletal variants: atlas bridging and clinoid bridging. American Journal of Physical Anthropology, 49: 193-204.

Sjøvold T. (1984) A report on the heritability of some cranial measurements and nonmetric traits. In: van Vark G.N. and Howells W.W. (eds.), Multivariate Statistical Methods in Physical Anthropology. D. Reidel, Dordrecht, pp. 223-246.

Velemínský P. and Dobisíková M. (2005) Morphological likeness of the skeletal remains in a Central European family from 17th to 19th century. Homo, 56: 173-196.

Weedon M.N., Lango H., Lindgren C.M., Wallace C., Evans D.M,
Mangino M., Freathy R.M., Perry J.R.B., Stevens S., Hall A.S., Samani N.J., Shields B., Inga Prokopenko I., Farrall M., Dominiczak A., Diabetes Genetics Initiative, The Wellcome Trust Case Control Consortium; Johnson T., Bergmann S., Beckmann J.S., Vollenweider P., Waterworth D.M., Mooser V., Palmer C.N.A., Morris A.D., Ouwehand W.H., Cambridge GEM Consortium; Caulfield M., Munroe P.B., Hattersley A.T., McCarthy M.I., and Frayling T.M. (2008) Genome-wide association analysis identifies 20 loci that influence adult height. Nature Genetics, 40: 575-583.

Woo T.L. and Morant G.M. (1934) A biometric study of the 'flatness' of the facial skeleton in man. Biometrika, 26: 196-250.

Yamaguchi B. (1967) A Comparative Osteological Study of the Ainu and the Australian Aborigines. Australian Institute of Aboriginal Studies, Canberra. 